\title{
UTILIZAÇÃO DA METODOLOGIA GRANADOS PARA A OTIMIZAÇÃO DE REDES HIDRÁULICAS MALHADAS
}

\author{
Antonio Farias Leal ${ }^{1}$ e IIeber Pimentel Gomes ${ }^{2}$
}

RESUMO

\begin{abstract}
O método Granados de otimização, desenvolvido para redes ramilicadas, foi associado à metodologia dos anéis de Hardy Cross e aplicado a redes malhadas. Os resultados obtidos mostram uma economia significativa no custo total das tubulações e revelam a potencialidade dessa ferramenta, que assume, definitivamente, o seu lugar no dimensionamento de redes pressurizadas.
\end{abstract}

Palavras chave: optimização, redes hidráulicas pressurizadas

\section{USE OF GRANADOS METHOD FOR LOOPED HYDRAULIC NETWORK OPTIMIZATION}

\begin{abstract}
This article extends Granados method from branched to looped networks and shows how to apply it to find a new solution to an already dimensioned real-world system, comparing the new solutions against the previous one. The conclusion is that cost optimization methods bring such a significant cost economy that definitily grants them to be almost mandatorily advisable for sizing pressured water distribution systems.
\end{abstract}

Key words: hydraulic, network, optimization

\section{INTRODUÇÃO}

As redes pressurizadas de distribuição de água vêm, há muitos anos, sendo dimensionadas através das técnicas de determinação de fluxos e pressões desenvolvidas por HARDY CROSS (Cross, 1936). Esta metodologia é largamente usada no dimensionamento de redes malhadas; entretanto, ela não aborda a questão da olimização econômica em seu algoritmo e trata apenas da parte hidráulica da rede, calculando a sua distribuição de pressão e de vazão. A otimização da rede fica sob a total responsabilidade do projetista que, diante das dificuldades envolvidas e do volume de cálculos necessários, não consegue atingir a solução de custo ótimo para a rede.

Na década de 1950, após o surgimento do computador digital de alta velocidade e das potentes técnicas de otimização, e também depois da discussão do problema de redes hidráulicas em artigos teóricos na década de 1960, parecia ser só uma questão de tempo, até que os projetistas pudessem fornecer alguns dados ao computador e este determinaria a rede de tubulação ótima para um sistema qualquer (ótima neste trabalho, refere-se àquela rede que atende às demandas com o custo mínimo). Já na década de 1980, os métodos de otimização de redes começaram a ser desenvolvidos e, em pouco tempo, foram aplicados a problemas reais; entretanto, a otimização de redes de distribuição ainda não é considerada ferramenta básica para os engenheiros projetistas; poucos são os que realmente usam esses mélodos de otimização para resolver problemas de rede de tubulação. Para a grande maioria dos projetistas, as normas práticas e a técnica de tentativa-e-erro permanecem como ferramentas indispensáveis com relação ao problema de se selecionar os componentes dos sistemas de distribuição de água. No Brasil, a quase inexistência, até bem pouco tempo,

${ }^{1}$ Professor Assistente - DEAg/ CCT/ UFPB. email leal (a) deag.ufpb.br.

2 Prolessor Adjunto - DEC/ CCT/ UFPB. email gomes @ lrh.ulpb.br. 
de metodologias de olimização de redes pressurizadas de distribuição de água que tivessem bons programas aplicáveis a computador, e a falta de conhecimento de outras desenvolvidas no exterior, levam a supor que esses seriam os molivos da não utilização dessas ferramentas nos projetos de redes hidráulicas pressurizadas. Felizmente, através de algumas metodologias com programas computacionais mais acessíveis, os quais estão se tornando disponíveis aos pesquisadores e aos engenheiros interessados nessa área de pesquisa, esse quadro está começando a mudar.

O objetivo deste trabalho foi realizar associação de uma metodologia de otimização econômica de redes pressurizadas ramificadas com o mélodo dos anéis de HARDY CROSS para a determinação de fluxos e pressões em redes malhadas e fazer uma aplicação prática da mesma.

\section{MATERIAL E MÉTODOS}

O método GRANADOS (Granados, 1990) é um algoritmo iterativo de otimização que se aproxima do método clássico da programação dinâmica. Ele fornece o custo mínimo de um sistema pressurizado e rami ficado de distribuição de água, em função da cota piezométrica de cabeceira do mesmo. Este método de otimização considera ainda a variação do preço das lubulações em função de seus materiais, diâmetros e classes.

No seu processo de olimização, o método GRANADOS pode ser dividido em duas etapas: 1) Determinação de uma solução prévia ou inicial. Esta solução inicial será composta pelos tubos de menores diâmetros admissíveis, em função da velocidade máxima admitida. 2) Redução da cota piezométrica de cabeceira da rede através de iterações sucessivas, a partir da solução inicial, obtendo-se, assim, um novo custo ótimo da rede de distribuição para cada decréscimo dessa cota.

O método GRANADOS foi desenvolvido para redes pressurizadas ramificadas de distribuição de água. Desta forma, os valores das vazões nos trechos da rede são conhecidos e não variam. Também é conhecido o sentido de cada uma delas, visto que só existe um sentido possível de fluxo. Nas redes malhadas sabe-se que não ocorre dessa maneira, visto que tanto o sentido quanto o valor da vazão de cada trecho são variáveis que dependem dos diâmetros dos trechos.

São muitos os cálculos necessários para o dimensionamento econômico das redes de distribuição através do método GRANADOS. Nesse trabalho foi utilizado um programa de computador conhecido como Otimização de Sistemas Pressurizados de Distribuição de Água, baseado no algoritmo do método de GRANADOS (Gomes, 1995).

Para a utilização do método GRANADOS em redes malhadas foi feila uma junção deste com o mélodo dos anéis de HARDY CROSS. Este último fornece as vazões e pressões em redes malhadas. O passo inicial é escolher alguns nós da rede malhada e supor que existe a confluência de fluxos para eles, chamados pontos estratégicos. As vazões dos trechos que se dirigem para esses pontos são arbitradas inicialmente e corrigidas sucessivamente através do método dos anéis de HARDY CROSS, até que a soma das perdas de carga em cada anel da rede seja zero; nesse momento, diz-se que o sistema está "balanceado".
Após a determinação do valor e do sentido da vazão de cada trecho, a rede malhada é seccionada nos pontos estratégicos e transformada em uma rede ramificada fictícia. A rede ramificada é dimensionada através da melodologia GRANADOS, que fornece os novos diâmetros e a nova cota de cabeceira da rede. Os resultados obtidos são os ótimos para essa rede ramificada inicial.

Depois da primeira otimização através de GRANADOS, o balanço hidráulico, realizado pelo método dos anéis, precisa ser refeito, pois, com a modificação dos diâmetros, surgem novas perdas de carga para cada trecho, as quais são diferentes das anteriormente calculadas; portanto, a rede volta à condição de não-balanceada. Novamente, a metodologia de HARDY CROSS é aplicada, desta vez utilizando os novos diâmetros fornecidos por GRANADOS, o que resulta em novas vazões e novas perdas de carga para cada trecho, em, seguida, a rede é submetida a uma segunda otimização através de GRANADOS, quando se verificado se existe redução de custos. Caso não exista mais nenhuma redução de custos, o procedimento é interrompido e a situação da rede antes dessa segunda otimização, é a solução ótima para a rede, ou seja, os dados de saída da última aplicação do mélodo dos anéis são os dados finais da rede otimizada. Caso exista ainda alguma redução de custos, o procedimento acima descrito é repelido até que não haja mais redução de custos. Geralmente, o número de repetições é menor ou igual a 4. Com esses artifícios, as redes malhadas podem ser dimensionadas e otimizadas através do método GRANADOS.

Nas redes ramilicadas otimizadas através de GRANADOS, o excesso de pressão deve ser igual a zero $(\mathrm{EP}=0)$ em pelo menos um nó da rede. Para as redes malhadas, o balanceamento de vazões e pressões realizado através de HARDY CROSS, após a otimização por GRANADOS, pode elevar um pouco as pressões nos nós, tornando lodos os EP's da rede diferentes de zero, portanto, a solução ótima obtida através da junção do método GRANADOS com o método de HARDY CROSS para uma rede malhada pode não apresentar nó(s) com $\mathrm{EP}=0$ na sua distribuição de pressão.

A Figura 1 mostra o algoritmo da junção do método GRANADOS ao método HARDY CROSS, esta junção permite que o método GRANADOS seja utilizado também para o dimensionamento de redes malhadas.

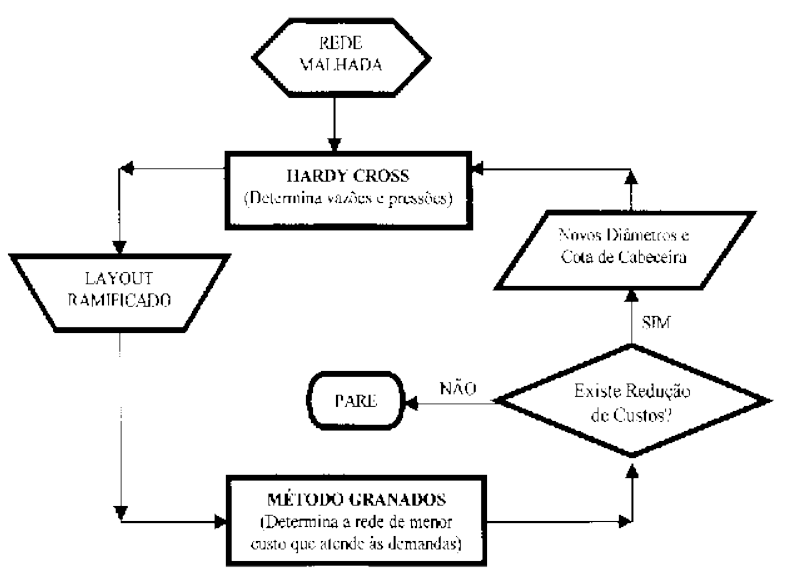

Figura 1. Algoritmo da junção do método GRANADOS com o método HARDY CROSS. 


\section{RESULTADOS E DISCUSSÃO}

O sistema escolhido para a aplicação do método GRANADOS adaptado a redes malhadas foi o de abastecimento do bairro do Bessa, na cidade de João Pessoa, PB, projetado pela CAGEPA (COMPANHIA DE ÁGUA E ESGOTOS DA PARAÍBA, 1982) através do tradicional método dos anéis de HARDY CROSS, Figura 2. Na época, foram utilizados os limites de velocidades máxima recomendados por Martins, 1973. Os cálculos desse projeto foram realizados visando atender às demandas requeridas de vazão e pressão, as quais são supridas através de um reservatório elevado já existente.

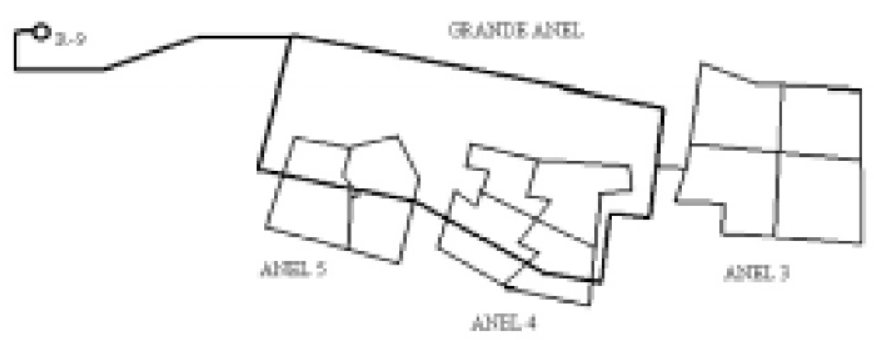

Figura 2. Traçado da rede do Bessa - Cagepa.

Na otimização do método GRANADOS as reduções de diâmetro ocorrem em todos os anéis do exemplo, aumentando as perdas de carga e fazendo com as pressões disponíveis nos nós sejam baixadas para os limites da pressão requerida, consumindo os excessos de pressão existentes em cada trecho onde ocorre a mudança.

A junção ao mélodo dos anéis de HARDY CROSS para a determinação das pressões e vazões funciona adequadamente para as redes estudadas; entretanto, a passagem de uma rede de layout malhado para uma de layout "ramificado" nem sempre é imediatamente possível. As dificuldades acontecem quando no "balanceamento" através de HARDY CROSS ocorre uma mudança no sentido das vazões nos trechos, a qual modifica o esquema do anel estudado, onde trechos que eram de montante passam a ser de jusante, e isto altera o layout da rede "ramificada" e aumenta o tempo gasto na otimização.

A Tabela 1 mostra o resumo dos custos das tubulações em valores da época do projeto, alcançados para os anéis através do método GRANADOS associado ao método de HARDY CROSS, utilizando os limiles de velocidades recomendados por Martins, 1973. A Tabela também indica o percentual de economia obtido em relação ao projeto realizado pela CAGEPA em cada um dos anéis.

Note-se que a economia é bastante significativa, média de $12,4 \%$, a qual, poderia ser ainda maior se não houvesse a
Tabela 1. Custo da tubulação de cada anel da rede

\begin{tabular}{cccc}
\hline ANEL & CAGEPA & GRANADOS & Economia $(\%)$ \\
\hline Grande Anel & $\$ 174.481 .640$ & $\$ 154.118 .672$ & 11.7 \\
Anel 3 & $\$ 46.779 .915$ & $\$ 41.164 .740$ & 12,0 \\
Anel 4 & $\$ 23.109 .434$ & $\$ 18.063 .900$ & 21.8 \\
Anel 5 & $\$ 7.443 .265$ & $\$ 7.145 .230$ & 4.0 \\
TOTAL & $\$ \mathbf{2 5 1 . 8 1 4 . 2 5 4}$ & $\mathbf{\$ 2 2 0 . 4 9 2 . 5 4 2}$ & $\mathbf{1 2 , 4}$
\end{tabular}

restrição da cota do reservatório já existente. No anel 5 ocorreu a menor redução devido ao menor número de trechos, e ao aproveitamento de tubulações já existentes. Ressaltam-se também os baixos valores das velocidades máximas recomendadas por Martins, 1973. Atualmente, já se admite velocidades muito maiores (GRANADOS, 1990) o que resulta em reduções de diâmetros muito mais significativas.

\section{CONCLUSÕES}

1. A adaptação do método GRANADOS às redes malhadas funciona adequadamente, facilitando e agilizando o trabalho de dimensionamento e da busca de uma solução-ótima que atenda às demandas com o menor custo possível.

2. Na aplicação escolhida, a economia obtida foi bastante significativa, mesmo com as restriçōes da velocidade, cota do reservatório e aproveitamento de tubulações existentes; isto comprova a aptidão e as vantagens dessa ferramenta para o dimensionamento e otimização de redes hidráulicas malhadas.

\section{REFERÊNCIAS BIBLIOGRÁFICAS}

COMPANHIA DE ÁGUA E ESGOTOS DA PARAÍBA CAGEPA. Projeto da Rede Distribuidora da Praia do Bessa. João Pessoa, Paraíba. 1982.

CROSS, H. Analysis of Flow in Networks Conduits or Conductors. Univ. Illimois Bull 286. Nov, 1936. USA.

GOMES, H. P., - Programa: Dimensionamento de Redes Hidráulicas Pressurizadas. Software, Versão 1.1 - Junho 1995. Campina Grande, Paraíba.

GRANADOS, A., Infraestructuras de Regadíos - Redes Colectivas de Riego a Presión. Servicio de Publicación de E.T.S.I. de Caminos de la Universidad Politécnica de Madrid. Espanha. 1990.

MARTINS, J. A. et al., Planejamento de Sistemas de Abastecimento de $\Lambda$ gua. Curitiba, Imprensa da Universidade Federal do Paraná. 281 p. 1973. 